\title{
An associative theory of estimating past dates and past prices
}

\author{
SIMON KEMP \\ University of Canterbury, Christchurch, New Zealand
}

\begin{abstract}
The theory-a location theory, in W. J. Friedman's (1993) terminology-assumes that time information such as the date of an event is increasingly likely to become unavailable with passing time. The theory suggests that when people are asked to date events whose time is unknown, they find and supply time information for the most similar event and context for which it is available. Simulations of the dating process were compared with experimental results and produced similar patterns of error and bias. The theory is extended to explain errors and biases in how people estimate past prices.
\end{abstract}

This article demonstrates that an associative theory can predict important features of how people date past events and how people remember past prices. Theories and findings about the way in which people estimate the dates of past events are discussed in the next section, in particular, the finding that people tend to remember remote events as occurring more recently than they did. The associative theory is then outlined, and computersimulated results obtained with a particular model of the theory are evaluated alongside the results of experiments in which people dated past events reported in the media. The theory should be able to explain biases in other dimensions besides time. Consequently, research on people's estimates of past prices is reviewed, and then simulated past price estimates are compared with the generic price estimates obtained from a survey. Finally, further predictions of the theory are discussed.

\section{Memory for Dates of Events}

There are a number of reasons why people's memories for when past events occurred appear to be worth studying. First and perhaps foremost of these is that our past lives often appear to us to be structured as an autobiography that follows a temporal sequence (see, e.g., Friedman, 1993). Second, the way in which we remember or misremember the times of past events often has practical consequences for the individual and for society (see, e.g., Bradburn, Rips, \& Shevell, 1987). Consider the importance in court cases of establishing people's whereabouts in time, for example. Third, although a number of pieces

\footnotetext{
Some of the research was done while I was on leave at the EuropaUniversität Viadrina, Frankfurt (Oder), Germany, and I am grateful to the Alexander von Humboldt Foundation for supporting this visit. I am also grateful to Alan Baddeley, Chris Burt, Mike Corballis, Bill Friedman, Arthur Glenberg, Gill Rhodes, Charles Thompson, John Wixted, and an anonymous reviewer for their helpful comments on earlier versions of the manuscript. Correspondence should be addressed to S. Kemp, Department of Psychology, University of Canterbury, Christchurch, New Zealand (e-mail: s.kemp(a)psyc.canterbury.ac.nz).
}

of evidence suggest that the way we remember the past is in some respects distorted (see, e.g., Bartlett, 1932), dates and other measures of time have the advantage of being quantifiable, so that the extent of the distortion can be measured.

In consequence, it is unsurprising that there has been considerable research in which participants have been asked when past events have occurred (see Friedman, 1993, and Thompson, Skowronski, Larsen, \& Betz, 1996, for reviews). Some of this research has been carried out in the laboratory, where typically the duration of rather short elapsed times has been studied, but there has also been a steady stream concerned with rather longer intervals of time and with events taken from the real world rather than laboratory tasks. Typically, people have been presented with brief descriptions of events and then asked to date them either by using calendar dating or by estimating how long ago the event took place.

Research of this kind requires the experimenter to present events whose times of occurrence are actually known. There are also advantages in being able to present the same events to different people. For these reasons, much of the research has required the dating either of events that have been widely reported in the media (e.g., When did the Berlin Wall come down?) or of well-known television programs (see, e.g., Friedman \& Huttenlocher, 1997; Squire \& Slater, 1975).

One very clear result obtained from this research is that people are not very good at dating past events. As a rule, few past events are correctly dated, and the size of the dating error is often large. Moreover, the more remote the event, the larger the error, on average. (Figure 6 shows typical errors obtained from an example of such research.) The finding is, of course, not unique to time information: In general, the more remote the event, the less detail is remembered about it (see, e.g., Warrington \& Sanders, 1971).

Second, it has frequently been found that people's estimates of the dates of past media events have been biased as well as inaccurate. Many researchers have re- 
ported that more remote events tend to be dated too recently, a phenomenon sometimes called forward telescoping, and it has also sometimes been found that rather recent events may be dated too remotely (see, e.g., Bradburn et al., 1987; Ferguson \& Martin, 1983; Kemp, 1988 , 1994, 1996; Lieury, Aiello, Lepreux, \& Mellet, 1980; Lieury, Caplain, Jacquet, \& Jolivet, 1979; Means \& Loftus, 1991; Rubin \& Baddeley, 1989; Wright, Gaskell, \& O'Muircheartaigh, 1997). The explanation of this pattern of bias is a focus both for the associative theory and, as we shall see shortly, for theories previously advanced by others.

A number of studies have asked people to date events from their own lives, and objective information about the events has been obtained from diaries. A few researchers have kept diaries themselves and then had themselves questioned about the events recorded (Linton, 1975; Wagenaar, 1986; White, 1982). Thompson and his co-workers (e.g., Larsen \& Thompson, 1995; Thompson, Skowronski, \& Betz, 1993; Thompson et al., 1996; Thompson, Skowronski, \& Lee, 1988) have carried out an ongoing program where students have been asked to keep diaries and then been questioned on their contents. An elegant variation has had 1 student keep a diary about the activities of his/her roommate (e.g., Thompson, 1982). Burt (1992) questioned volunteers who had kept diaries for personal reasons about their entries.

Although the accuracy of dating of the autobiographical events recorded in diaries is typically rather higher than for media events, errors are frequent and tend to increase with the age of the event. Moreover, the pattern of bias found with media events has also been found with autobiographical events (Burt, 1992; Huttenlocher, Hedges, \& Bradburn, 1990; Huttenlocher, Hedges, \& Prohaska, 1988; Thompson et al., 1993; Thompson et al., 1996).

There are a few studies in which people have been asked to date historical events - that is, those occurring typically before the individual was born (e.g., Bratfisch, Ekman, Lundsberg, \& Kruger, 1971; Kemp, 1988, 1994; Smith \& Tomlinson, 1977). For both media and autobiographical events, there should be a very high correlation between how long ago the event occurred and the age of the memory for the event, but the age of a historical event is substantially uncorrelated with the age of the memory. As is discussed below, studies of dating historical events are sometimes useful in deciding between the different theories that have been suggested as mechanisms for dating events. For the present, it is worth noting that historical events are not generally dated accurately, that the dating error tends to increase with the age of the event, and that they too are subject to the same pattern of dating bias as media events.

Different theorists have suggested a number of processes that people might use to estimate the times of past events. Friedman (1993) has classified the different types into distance-based theories, location-based theories, and theories based on the relative ordering of pairs of events. "In the distance-based theories, information about the age of a memory is created by processes that operate between the time of encoding and the time of retrieval, like the radioactive decay that makes carbon dating possible .... [Location-based theories] rely on information that is laid down at the time of encoding and later retrieved, just as the style of a piece of pottery can later reveal the period when it was made" (Friedman, 1993, p. 45). An important theoretical point is that, although locationbased processes, and in particular reconstruction, appear to often be of major importance, the other processes may also operate in particular situations (Friedman, 1993, 1996).

Both distance and location-based theories have been suggested to account for the patterns of errors and bias found when events, and particularly media events, are dated. One distance theory suggests that memories are chronologically organized but that the time scale used is transformed or compressed, so that remembered time becomes a power function of the actual elapsed time with an exponent of less than 1 (Bratfisch et al., 1971; Ferguson \& Martin, 1983). This approach, which clearly resembles that taken by Stevens (1975) to account for the relationship between, for example, the perceived loudness of a sound and its intensity, accounts nicely for why more remote events might be perceived as too recent. However, it is not easy to see why this theory predicts that the dating error should increase with elapsed time. Moreover, it does not easily account for the finding that quite remote well-known events are often dated quite accurately. To explain this phenomenon in the time compression model would require that the power function relating date estimates to actual dates has an exponent that varies with how well known the events are. Well-known events would require an exponent at or close to 1 ; lesser known events would require a smaller exponent. Finally, the assumption that people's judgments are consistently and irrationally distorted by failure to allow for a transformation occurring at a previous level of information processing is one that has given rise to discomfort in a number of theorists (e.g., Huttenlocher et al., 1988; Rubin \& Baddeley, 1989).

Another version of distance theory suggests that people's estimates of the time of past events is based on the strength of the trace for that event (e.g., Friedman, 1996). One variant of this theory, sometimes termed the accessibility hypothesis (Bradburn et al., 1987; Brown, Rips, \& Shevell, 1985), takes the amount remembered about an event as a measure of trace strength. Brown et al. found that events about which more could be remembered were, ceteris paribus, dated more recently, as the hypothesis indicates, but a number of subsequent researchers (Burt, 1992; Kemp, 1988; Means \& Loftus, 1991; Thompson, et al., 1988; Wright et al., 1997) have 
not replicated this result, finding simply that events about which subjects had more knowledge were more accurately dated.

The most likely explanation for the discrepancy in results is that trace strength is only a weak temporal cue that is often swamped by other processes (Friedman, 1996), and the failures to replicate arise from subsequent researchers using techniques that were not as sensitive as those of Brown et al. (1985) to weak effects. Empirical support for this explanation comes from Kemp and Burt (1998), who found, consistent with the accessibility hypothesis, that estimates of recency of news events measured by the strength exerted in squeezing a dynamometer were correlated with the vividness of the memory for the events when their actual dates were controlled for. Further evidence comes from a series of studies by Friedman and his co-workers (e.g., Friedman, 1996; Friedman, Gardner, \& Zubin, 1995; Friedman \& Kemp, 1998) on time estimation in children. Such participants are too young to use abstract or constructive processes, but they do display some knowledge of past time that presumably is mediated by a distance process.

A further problem with explaining forward telescoping via the accessibility hypothesis is that it predicts a bias opposite to that actually obtained. Events about which much is known are also those most accurately dated, and in general these show relatively little dating error in any direction. Events about which little can be remembered should also be those with the weaker traces, and should, on average, be recalled as more remote than the better remembered events. Hence, they should usually be remembered as more remote than they actually were. However, as stated above, the empirical result is that the more remote, less well-known events tend to be dated too recently.

Two other empirical findings create difficulties for any kind of distance-based theory. The first is the wellreplicated phenomenon (Friedman \& Wilkins, 1985; Larsen \& Thompson, 1995) that people may on occasion be able to estimate correctly the fine grain (e.g., the day of the week an event took place) but not the coarse grain (e.g., the year the event took place) of the time of occurrence of an event. It does not seem likely that the age of the memory could be used to generate accurate finegrained estimates in these cases. Second, the fact that similar patterns of dating error are obtained with historical events, as with events about which people learn when they occur, argues against age-of-memory effects being responsible for these patterns.

Both Friedman (1993) and Thompson et al. (1996) concluded that our memory for the time of past events is largely based on location-based processes and particularly on reconstructive processes. "The process of reconstruction is assumed to draw on a rich knowledge of social, natural, and personal time patterns ... and a small minority of salient events for which exact dates have been learned... . The essence of a reconstructive model is that aspects of the memory are combined with separate knowledge of time patterns to infer when the event probably occurred" (Friedman, 1993, p. 47).

As this quotation suggests, reconstructive processes are themselves a rather assorted mixture. One could, for example, reconstruct the date of a political event from one's knowledge of the date of election or resignation of a politician involved, by a logical inference of the likely time between it and another known political event (see, e.g., Burt \& Kemp, 1991), by reference to some event or condition in one's private life, or by some combination of all three.

Perhaps the most compelling evidence that participants in dating experiments make use of reconstruction comes from their own introspections of the processes they use. People who are asked to date their autobiographical events and then to indicate how they did so frequently report using some kind of reconstruction. For example, Burt's (1992) diary participants reported reconstructing about $10 \%$ of their date components using landmark event information, and nearly $20 \%$ reported using the cue information provided by the experimenter. Thompson et al. (1996, chap. 6), reviewing the results of their earlier diary studies, found reports of some variety of reconstruction for up to $60 \%$ of the more remote events. Participants dating media events and even historical events have also reported using reconstruction (see, e.g., Friedman, 1987; Friedman \& Wilkins, 1985; Kemp, 1994), but the frequency of use of such processes is generally a little lower for media than for autobiographical events and lower still for historical events.

Overall, the reported use of reconstructive strategies for events is associated with errors that are greater than those for events whose dates people claim to know and less than those for events that they report simply guessing (see, e.g., Baddeley, Lewis, \& Nimmo-Smith, 1978), consistent with the idea that people attempt reconstruction when the actual dates are unavailable. It is also known that people can improve their dating ability with experimenter-aided reconstruction (Loftus \& Marburger, 1983).

Although people's introspections are evidence for reconstruction, it does not follow that reconstruction must always be a conscious process (see Friedman's 1993 definition, above). Even when people claim to be purely guessing the dates of events, their estimates do show some correlation with the actual dates of the events (see, e.g., Kemp, 1994). Most important for the aim of the present paper is that the tendency to date remote events too recently occurs with a variety of reconstructive strategies as well as when people claim to have no knowledge of the event at all (Kemp, 1994). The associative theory proposed in this paper and the boundary effects and rounding models proposed by Huttenlocher and her colleagues (Huttenlocher et al., 1990; Huttenlocher et al., 
1988) are similar in terms of making no assumptions about people's awareness of the reconstructive processes they employ.

The boundary effects model was proposed independently by Huttenlocher et al. (1988) and Rubin and Baddeley (1989) to explain dating bias without having to assume a time compression for which people failed to allow when they dated events. The basic idea is that dating bias arises from the combination of error in the remembered times and the presence of boundaries that are imposed by the participant or the circumstances of the recalled event. For example, if you know an event happened during your 1st year at university, then it must have occurred between the two boundaries formed by the start and end of the university year. Such a theory predicts dating bias quite naturally. For instance, events near a distant boundary will on average be dated too recently because misremembered dates are "free" to become more recent but not more remote. Similarly, events occurring just before the more recent boundary should tend to be remembered as occurring more remotely than they did.

It is likely that in some recall situations, boundary effects are an important cause of dating bias. For example, Huttenlocher et al. (1988) asked moviegoers to date films that were shown only during the quarters of the university year-and hence possessed natural boundaries - and the results obtained were rather well described by the boundary effects model. Burt (1992) and Thompson et al. (1996, chap. 7) interpreted the dating bias obtained in their diary studies, which had boundaries defined by the beginning and the end of the diary-keeping period, in terms of these effects. However, the evidence from studies in which media or historical events have been dated indicates that boundaries are not the only important cause of dating bias. The critical point is that these studies still demonstrate dating bias, although in most cases, unlike in the diary studies or in Huttenlocher et al.'s (1988) study of moviegoers, it is not easy to see what the boundaries are. It is true that the time of the experiment often provides a recent boundary, but this would hardly explain why remote events tend to be dated too recently.

As an example of the findings, Lieury et al. (1979) found systematic dating bias despite not supplying boundaries to their participants. Moreover, the extent of the dating bias was found to vary with the type of event: Sports events, for example, exhibited more forward telescoping than political events. Thus, if dating bias arose from participants imposing their own boundaries in this experiment, they must have used different boundaries for different types of event.

Kemp (1994, Experiment 1) had participants date media events in two conditions. In one, participants were informed that all the events lay between two dates (as happened in some earlier studies-e.g., Ferguson \& Martin, 1983; Kemp, 1988); in the other, no boundaries were suggested. The boundaries were effective in that participants in the bounded condition placed many more dates inside the boundaries, but the amount of dating bias was virtually identical in the two conditions. Of course, participants might impose their own boundaries, but Kemp (1994, Experiment 2) found much the same dating bias regardless of whether or not participants subsequently recalled estimating and imposing boundaries when dating media events. Similar results were obtained when participants dated historical events.

Finally, if participants were to supply their own boundaries when dating media events, it might be expected that younger participants would supply more recent remote boundaries than older participants, and hence, on average, would tend to date media events more recently. However, Kemp (1995) found no difference in date estimates between groups of younger ( 22 years or younger) and older ( 25 or older) participants.

Huttenlocher et al. (1990) also proposed that rounding might contribute to dating bias. In their experimental research, participants who were asked how long ago an interview had taken place tended to round the periods of elapsed time (e.g., from 33 to 30 days). In Huttenlocher et al.'s (1990) model, bias results from the combination of two aspects of the way rounding is assumed to take place. Prototypical values (e.g., 7 days, 30 days) are assumed to become more sparsely distributed with elapsed time, and participants are assumed to choose the nearest prototype. For example, take the prototypic values of 10 , 14 , and 30 days. An assigned value of 14 days should occur for all days between 12 (midway 10 and 14 ) and 22 (midway 14 and 30 ) days. Then, if the actual days are evenly distributed, a tendency to date too recently will result.

Two theoretical problems arise with trying to apply this model. First, one of the critical assumptions - that people should place the division between the prototypes in the middle of the range-appears a priori no more likely than that they should choose a division closer to the lower value (in which case bias would not result from rounding). Second, it is not clear what implications the model has for studies in which participants are asked to assign a date to an event rather than to say how long ago it was.

The small amount of subsequent research directed at the rounding hypothesis is not encouraging either. Thompson et al. (1993) found little evidence for rounding effects when they asked people to provide dates for their personal events. Kemp (1994) found that participants often did round the dates of both media and historical events-for example, more historical date estimates than expected ended in $0-$-but there was no tendency for such rounded dates to be more subject to dating bias than dates that showed no evidence of rounding.

\section{Principles of the Association Theory}

The theory presented here resembles the theories proposed by Huttenlocher et al. (1988), Huttenlocher et al. (1990), and Rubin and Baddeley (1989) in retaining an undistorted representation of time and in seeking to incorporate reconstructive processes, but it differs in sev- 
eral important respects. In the former theories, time information is assumed to be available for all events, but is subject to random distortion. In the present theory, when time information is available for a particular event, it is assumed to be accurate. However, time information is not available for most events.

The theory rests on three major assumptions: that the events people experience form contexts and become associated with one another so that similar or related events tend to cue one another in memory; that time information, like other kinds of information, becomes more difficult to recall as the retention interval lengthens; and that the dates of events whose time information has been forgotten are estimated after searching through similar experiences for time information. We consider the broad issues involved and then narrow down toward a more specific version of the theory that can be computer simulated.

The first assumption is really a presumption for any kind of associative theory of memory, since memories for individual events or indeed memories for schemas (see, e.g., Brewer \& Nakamura, 1984) clearly do become linked with one another. The idea that memories are linked by associative networks is a very old one in psychology, dating back at least as far as Aristotle (Sorabji, 1972), but it has not been neglected by modern psychologists (e.g., Anderson, 1983; Anderson \& Bower, 1974). The critical point for the present theory is that similar or related memories tend to cue one another. In the present context, it is noteworthy that similar types of events do seem to be organized together in long-term memory (Brown, 1990), and that when similar events are presented for dating, the estimated dates tend to cluster together (Kemp, 1987b).

The particular model presented below assumes a simple contextual index of the respondent's life and his/her mental representation of the events that take place during it (see Conway, 1996). For convenience, time is thought of as broken into discrete chunks (called events below), and each event contains information about different matters that concern the respondent. These can be particular to the individual-for example, where he/she is living-or public - for example, an earthquake that affects the participant him-/herself or is reported in the media. Some contexts will register only for one event - a news event for which there is no follow-up, for example-whereas others will register in a number of events-for example, knowing who the president of the United States is.

As a simple example of how this might operate, consider the two "events" to be 2 consecutive weeks in your life. If you continue living in the same house and with the same partner, these contexts will be the same. There is an ongoing news story about your city that features in the media in both weeks. The lst week, however, you spend skiing, which you do once every year. (The context for this week will thus tend to resemble the other skiing weeks you have had.) In the 2 nd week, you go to a wedding, and also there is a surprising major news event - the sudden death of a world leader.

The particular version of the assumption employed below, which requires all the different types of event an individual experiences to be placed on a single dimension, is a simplification not only of how people perceive and remember events but also of the way in which events actually relate to each other. For example, a detailed model of how people's perception of the political process varies over time requires an understanding not only of people's perceptions but also of the unfolding of the political process itself. Moreover, not one but several such models are needed, for political events probably form only a minor strand in the structure of most people's memories. On the other hand, for our present focus, oversimplifying should fail safe in a theoretical sense, since what can be explained with a simple theory can also be explained by a more complex theory using the same principles.

The second assumption concerns the availability of time information for events. The theory assumes that time information, such as the year and month of the occurrence of an event, is often likely to be available when the event actually takes place, but with the increased lapse of time after the event, this information is progressively less likely to be available. The theory is silent as to whether the unavailability occurs because the information is completely lost from memory or merely because it becomes irretrievable in practice. If time information is available, then it is produced when someone is asked to date an event, and the event will then be dated accurately. When time information is not available, another method of dating occurs. For simplicity, the particular model presented here considers only one kind of time information, but more than one (e.g., year, month, day of the week) could also be modeled.

There is a good deal of evidence that people's ability to provide exact dates or other time information decreases with increasing time from the event. For example, Thompson et al. (1996, chap. 7) found that their diarists' ability to date personal memories decreased in exact proportion with retention interval. Kemp (1996, Experiment 1) asked simply for the recall of any news events that participants thought they could date accurately. Of those that could be checked, $41 \%$ were correct as to year and month and a further $31 \%$ gave the correct year. The distribution of dates given in this experiment was markedly skewed: Nearly half the dates were in the preceding 12 months. Information about the time of events is not unique in becoming less available with passing time: A number of studies have shown that both people's ability to recall detail generally and their ratings of the clarity of the memory decrease with elapsed time (e.g., Squire \& Slater, 1975; Thompson et al., 1996, chap. 3; Warrington \& Sanders, 1971).

The third key assumption is that when time information is not available for a particular event, an associative 
search takes place in an attempt to reconstruct the temporal information. In broad terms, the search is assumed to focus primarily on events that have a similar context to that of the target. The theory does not assume that any of the process of recall is accessible to introspection, but as an illustration, consider being asked when Mathias Rust landed his private airplane in Moscow's Red Square. Now, it may be that you can simply recall the time information (May 1987). More likely, you will not remember the date but only something of the context, and this will lead you to a time estimate. For example, you might link the event to the upheavals in Eastern Europe, recall that the Berlin Wall came down in 1989 , and reason that Mathias Rust's flight occurred about then. Alternatively, you might recall the event as occurring about the same time as you got married.

In the particular version of the theory outlined below, it is assumed that people search the contexts of other similar events in decreasing order of similarity until one is found that does have a date associated with it. The date of this similar event is then taken as the date of the target event. Obviously, to enable this search to take place, some measure of the similarity of the different events needs to be arrived at. The particular version presented below assumes that the different types of context are simply added together into a single context index. However, in reality it is likely that arrays of different types of contexts (e.g., political knowledge, the participant's work and love life, etc.) are searched more or less independently. Moreover, the search process may vary greatly with the task and the resources the individual wants to devote to it (see, e.g., Anderson, 1991).

Before moving on to a simulation of the process, it is worthwhile to consider two general predictions of the theory.

First, it is fairly easy to see that the theory predicts that remote events should be dated more inaccurately. This follows from the second assumption: Available time information is sparser for more remote events, and hence, even if the associative process always produced the best possible remaining time information, this information would be less accurate than for more recent events.

Second, and more critically, more remote events should tend to be dated too recently. This follows because time errors produced by the associative search (i.e., when the time information for the particular event has been forgotten) should tend to be too recent, because older events are less likely to have available time information, and hence will not be candidates for matching from the associative search.

As a simple extreme example, consider the situation where either associations between events are completely random or (equivalently for this example) where there is no tendency for similar events to be near in time. In this case, any event whose date was unknown would be dated according to the distribution of the events for which a date is available. Thus, excluding those whose events whose dates are known, the median remembered date will be the median of all events with dating information, and, since the distribution of events with time information is strongly negatively skewed (the second assumption), remote dates will tend to be dated too recently. Accuracy will also increase for the more recent periods, simply because there is more chance of correctly dating these.

It is easy to see that, although this simple model provides a qualitative explanation of these two phenomena, it is not a plausible scenario generally. If we exclude all the events that were dated exactly, the average date assigned to all the rest would be the same, but, as noted, reconstructed dates typically demonstrate a reasonable correlation with the actual dates, and even guesses normally show a positive correlation.

The next sections outline a model of how people date events in sufficient detail to enable computer simulation. The results obtained with this simulation are then compared with those obtained when people have been asked to date samples of media events.

\section{SIMULATION 1}

\section{Method}

The simulation program consisted of two parts. The first part of the program calculated a context index for each period and then "forgot" much of the time information. It thus models the memory of individuals at the time of participation in a dating experiment. The second part simulated how people would date 20 events.

For the simulation, 500 events were used. The model assumes that a summary of event and personal information is recorded and remembered for each event. This information-called in what follows the context index - can be used by individuals when they try to remember dates.

For each event, a random component summarized the contribution to the context index of public or shared events and simulated the tendency for a number of different individuals in a group to share some memories. The empirical research suggests that a particular event may have its own source of bias and be remembered as unusually recent or unusually remote. For example, Wright et al. (1997) asked a large sample to date two remote media events and found that one was on average dated too remotely - a reminder that not all remote events are dated too recently-and the other was dated too recently. Consequently, the context index in the model contains a public component, which was randomly chosen from a rectangular distribution with an upper bound of +0.25 and a lower bound of -0.25 . The progress of the public component over the 500 different events was generated only once in each simulation (i.e., was the same for all repetitions; see below), simulating the fact that in a media-event dating experiment, the same event is presented to a number of participants.

The other two components varied with repetitions and thus reflect individual differences. The underlying context component may be thought of as a very crude approximation of the life history of an individual. This component was determined by a random walk beginning with a value of 1.0 in Period 1 . On $20 \%$ of the succeeding periods (determined by random generation), the underlying component was increased by 0.04 , and on $20 \%$ it was decreased by 0.03 . Otherwise it was unchanged. Effectively this component crudely reflects the structure of people's lives changing slowly over time. In real terms, this might reflect someone's occupation, partner, children, or circle of friends. 
A third everyday random component was also chosen each period. It also had a rectangular distribution with an upper bound of +0.25 and a lower bound of -0.25 . Like the underlying context, this third random component was chosen anew in each of the 40 repetitions. This component roughly reflects the variety in everyday life. For example, if I go to see a movie one evening, the context of going to the movie has similarities to other occasions when I have been to the movies, and this "movie context" may have little connection with other events in my life. Or if you go skiing every so often, these ski experiences will tend to resemble one another.

The context index for each event simply consisted of the arithmetic sum of the public, underlying, and third components. A single example of how the context index could vary over 500 events is shown in Figure 1A. Figure 1B shows the interval from event 151 to event 200 in more detail.

Time information simply consisted of the event number. Whether this was remembered was determined randomly. Remembering took place with a probability equal to $0.02+0.4 \times \exp ($ event 500) $/ A$, where $A=100.0$. The constant $A$ is a measure of how rapidly the time information is forgotten. (Smaller numbers produce more rapid forgetting.) Figures $1 \mathrm{~A}$ and $\mathrm{IB}$ show the distribution of events for which there was time information for a single example.

In the simulation, at the time of the event actually occurring, the "participant" had a $42 \%$ chance of knowing the "date," at asymptote a $2 \%$ chance. Although it is not easy to relate these figures precisely to empirical results, they are not unreasonable. Kemp (1994, Experiment 1 ) found that $7 \%$ of all media events were accurately dated, averaged over all the dates. Thompson et al. (1996, chap. 7) found an asymptote for accurate event dating at around $10 \%$, but the time intervals measured were relatively short and, as noted, personal events are generally better recalled in any case. Their data also portray the gross features of an exponential decay function: more rapid initial decline followed by slower decline. It is, of course, possible that the real forgetting function has some other form (e.g., a power function), but the precise form of the function is not of much consequence for this simulation

In the second part of the program, which simulated recall, 20 events were chosen to represent news or other experimenter-provided events. The first occurred at Event Number 110 (to avoid strong remote boundary effects) and then at intervals of 20 up to 490 .

If the event number could be remembered, this was taken as the estimated time. If not, the program searched the events for which a time could be remembered until that with the closest (absolute difference) context index was found. This number was then accepted as that of the target event. As an illustration of how the program works, consider that in Figure $1 \mathrm{~B}$ the event occurring at 170 is to be dated. There are only two events for which there is time information in the range shown, and the later of these (at 188) clearly has the more similar context index. Thus, if the choice had been restricted to the range 151-200, the event occurring at 170 would be assigned the number 188 .

Finally, 40 repetitions of this process were performed. Repetitions in the simulation can be thought of as analogous to different participants in dating experiments: Forty is a typical number of individuals who might serve in a condition of a dating experiment (e.g., Kemp, 1994, Experiment 1). Note that for all 40 repetitions, the same public component of the context was used.

\section{Results}

Figure 2 shows the median results obtained from a single run of 40 repetitions of the program. Also shown in Figure 2 is the mean result from performing 50 separate simulations (i.e., a total of 2,000 repetitions, but with 50 distinct public components). By comparison, Figures 3 and 4 show two experiments in which participants were asked to write down the year and month of the occurrence of 28 events reported previously in the media. The two experiments (Kemp, 1994, Experiment 1 control condition and Kemp, 1996, Study 1 subsidiary experiment) employed 39 and 45 participants, respectively. In neither case were boundaries provided by the experimenter. The two experiments differed procedurally only in the actual events that the participants were asked to date. The slopes and intercepts of the regression lines of the data shown in Figures 3 and 4 are somewhat different, but both show a similar pattern of results. Comparison of these two figures with the simulated results suggests that the pattern of actual results is reasonably well simulated by the program. (Note that the regression line slopes of the simulation and the actual results are directly comparable, but the intercepts are not.)

Features to note in the figures include, first, that in all cases the slope of the fitted regression line is less than 1. Second, both simulation and experimental results show considerable forward telescoping. The more remote estimates generally lie above the line of accurate estimation, where estimates and actual periods are equal, and the regression line of the estimates crosses the line of accurate estimation at a point more recent than the midpoint of the actual dates.

In contrast, there was limited backward telescoping in either the simulation or the experimental results. (The most recent period estimate in the simulations was actually consistently less than 490 - the average over 50 runs was $482[S D=10]$ - but this is not easy to see in the figure.)

The spread of median estimates from the single simulation resembles that shown in the experimental results. (One would not expect this feature to be manifest from the average of 50 runs.) In both, the error seems to increase with the age of the event. This feature is more clearly shown in Figures 5 and 6, which show the median absolute errors for each event as a function of the event period or actual date. (These were calculated by first subtracting the actual date or event period from the date estimate for each event and participant or repetition. The median value of these errors, regardless of sign, was then calculated for each event.) Obviously for both the single-run simulation and the experimental results (Kemp, 1994, Experiment 1 control condition), more remote events were more inaccurately dated.

For the first simulation only, the least squares lines obtained by regressing estimated event times on actual event times for the 40 individual runs were calculated. A median slope of .64 and a median $R^{2}$ of .36 resulted. These compare with median slopes of .74 and .83 and median $R^{2}$ values of .26 and .15 for the individual participant results obtained from the two experiments (Kemp, 1994, and Kemp, 1996, respectively).

\section{Discussion}

Overall, the simulation provides a reasonable approximation of the kinds of results obtained when people are asked to date media events, and thus demonstrates that 


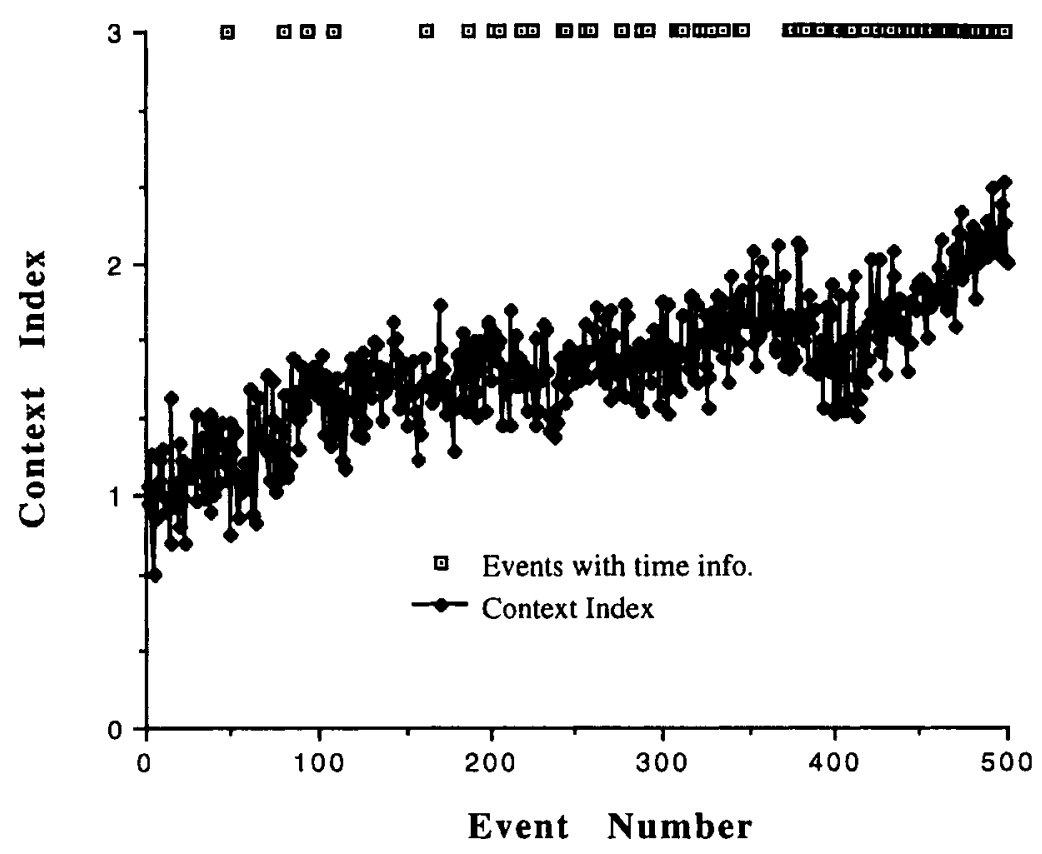

Figure $1 \mathrm{~A}$. Context index and events for which time information was actually available for a single repetition in Simulation 1 .

the association theory is capable of explaining the pattern of dating errors obtained in such experiments.

The particular model presented here assumes that when people are asked to date an event, the event and personal context (i.e., the context index) is always avail- able. A more realistic but clearly more complex model would assume two associative processes, one going from the event information provided to the personal context information and the other using this information to try to obtain time information. On the same theme, if the sin-

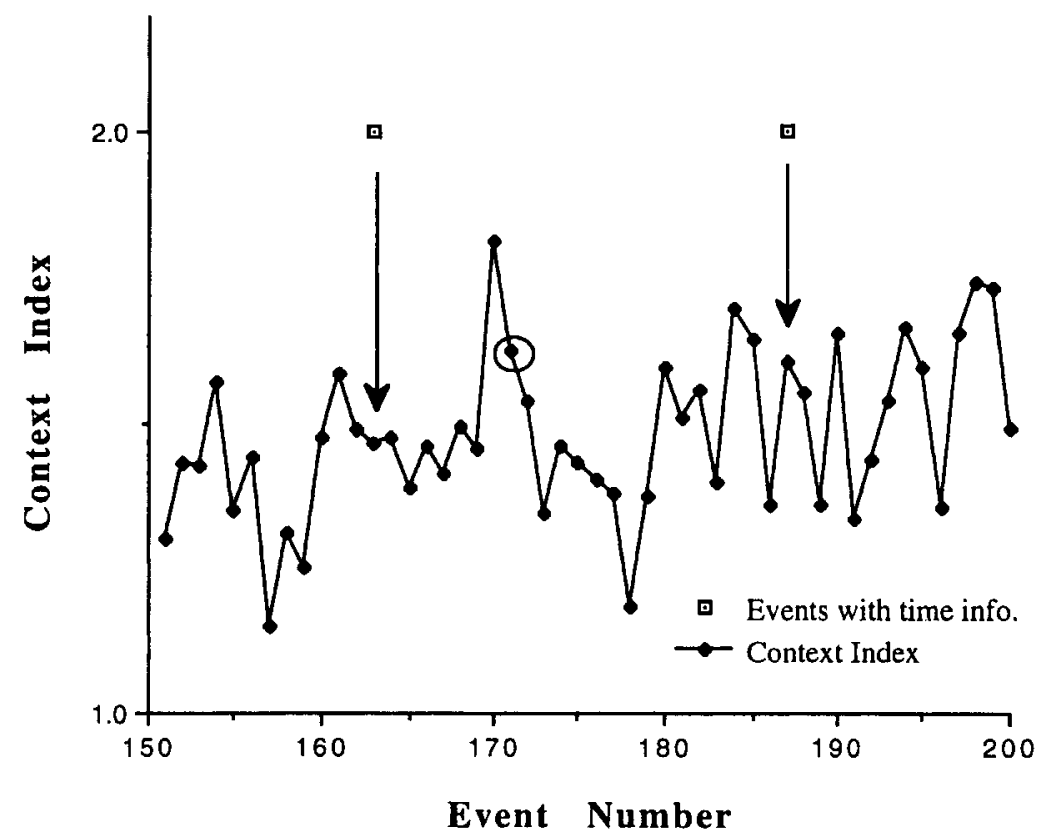

Figure 1B. Magnification of Events 151-200 from Figure 1A. The arrows indicate the two events in this segment with time information. The circled event (No. 170) has a context index closer to the later of these events (see text). 
gle context index were replaced by a multidimensional one, associations between the event and each of these dimensions could be incorporated. A model of this kind would produce the same pattern of errors as that demonstrated by the simpler version outlined earlier, and would probably be a more realistic way of encapsulating the kinds of processes people use when dating personal events.

A reasonably natural extension to the present theory explains how historical events might be dated. Clearly for historical events the assumption that the dates of older events are more likely to be forgotten because of the increasing age of the memory must be rejected, since memories for learning older historical events will not normally be older than for more recent ones. Nonetheless, provided that respondents have a kind of context index that describes their knowledge of historical events, the theory presented here once again predicts dating bias. The critical point is that time information for historical events is again much more likely to be available for recent events, not because the older information is more likely to be forgotten, but because it is less likely to have been learned in the first place. How many people know more about the events of the 18th century than those of the 20th? When people are simply asked to remember and date all the historical events they can, they show the same kind of bias to recency as they do when they are asked to remember and date news events: Most of the events turn out to be 20th-century ones (Kemp, 1996).
A key feature of the associative theory advanced here is the presumption that temporal information has no special status in the way memories are organized, and hence that it may be forgotten in much the same way as any other kind of information. If this is so, then biases like the forward telescoping of time also ought to exist in the way we recall other information.

It is well known that systematic biases in long-term memory are not restricted to the dates of past events. For example, Bartlett's (1932) research on people's memory for stories demonstrated that over several years there was systematic distortion of the originals. However, although dates are readily quantifiable, the systematic distortions that Bartlett described are not, thus making it rather difficult to develop precise models of the distortions.

Nonetheless, there are quantities apart from time that display quantifiable distortion. One such quantity is people's memory for visual area, where the relative areas of parts of a picture are frequently misremembered (see, e.g., Intraub, Bender, \& Mangels, 1992). Another is people's memory for past prices, and the following sections outline the empirical results obtained and show how some of the features of these results are produced by an associative model.

\section{MEMORY FOR PRICES}

The inflation that was widespread in Western economies in the 1970 s and 1980 s gave rise to considerable research. Most of this research has little relevance to

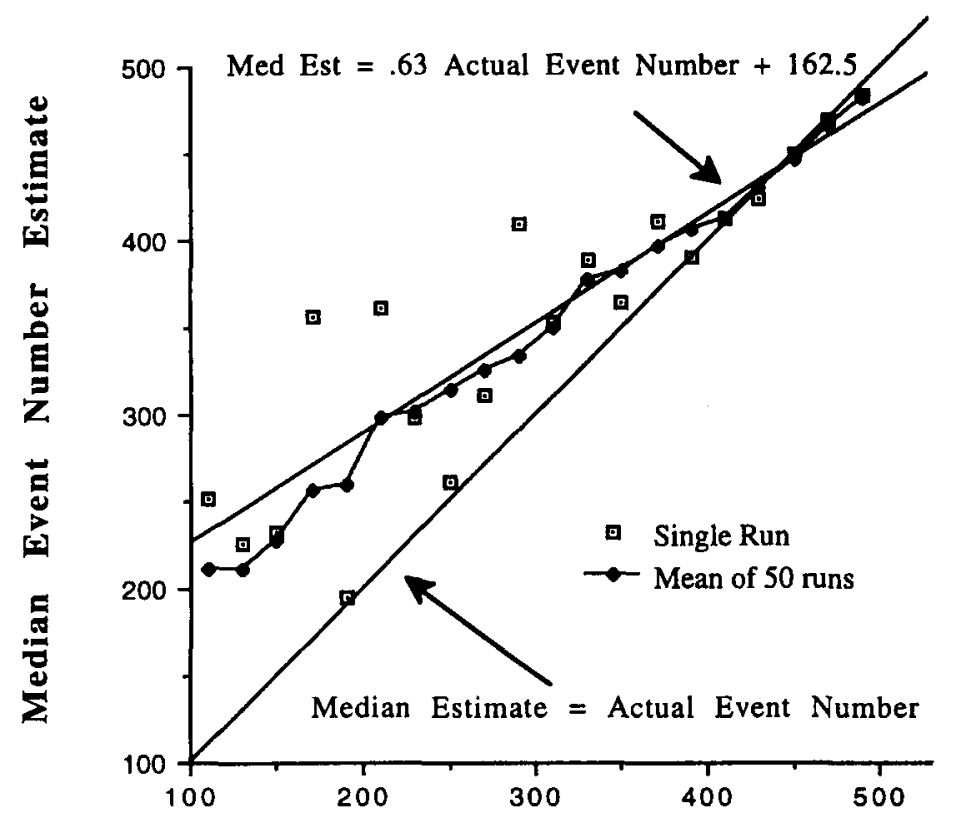

Actual Event Number

Figure 2. Results of Simulation 1. Median event time estimate (from 40 repetitions) as a function of the actual event number. The equation of the least squares regression line is shown $\left(r^{2}=.78\right)$. The mean results from 50 different simulation runs are also shown, as is the line: median estimate = actual event number. 


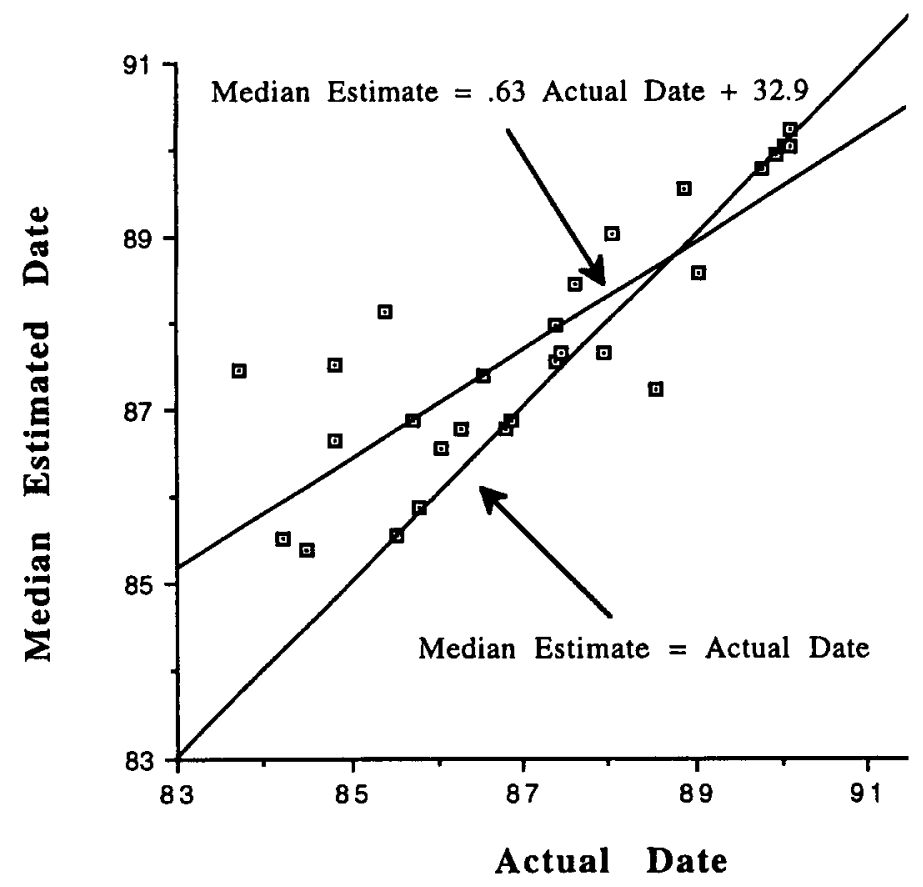

Figure 3. Median estimated date of 28 media events as a function of their actual datt. Data taken from the control condition of Kemp (1994, Experiment 1). The equation of the least squares regression line is shown $\left(r^{2}=\right.$ .71). Also shown is the line: median estimate $=$ actual date.

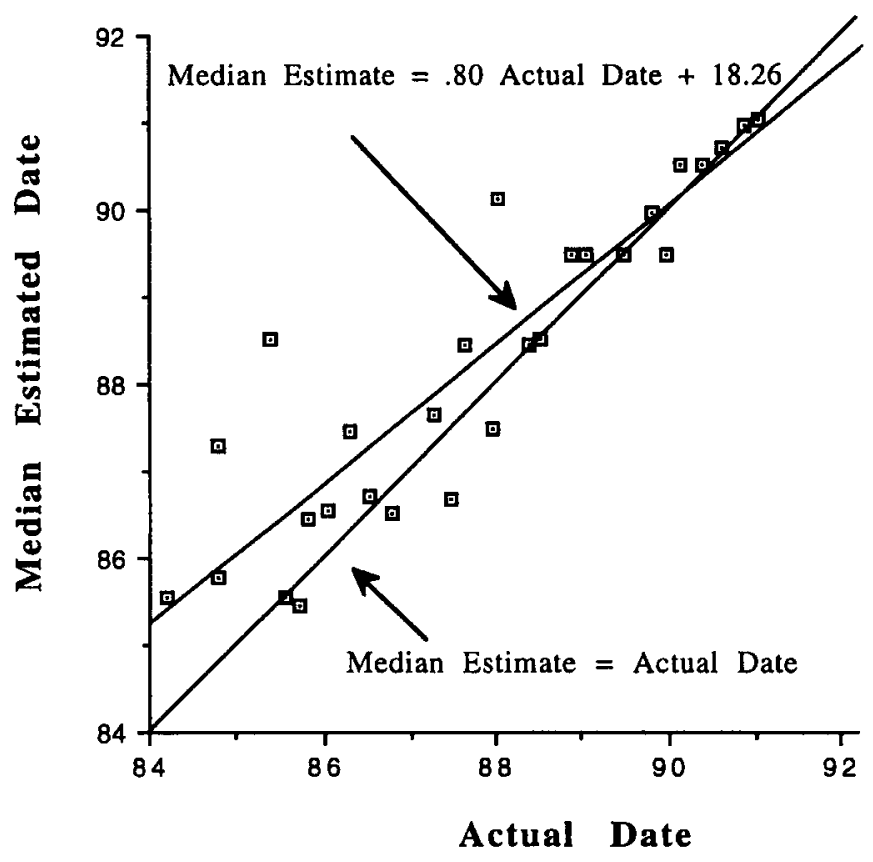

Figure 4. Median estimated date of 28 media events as a function of their actual date. Data taken from the subsidiary experiment of Kemp (1996, Experiment 1). The equation of the least squares regression line is shown $\left(r^{2}=.81\right)$. Also shown is the line: median estimate $=$ actual date. 


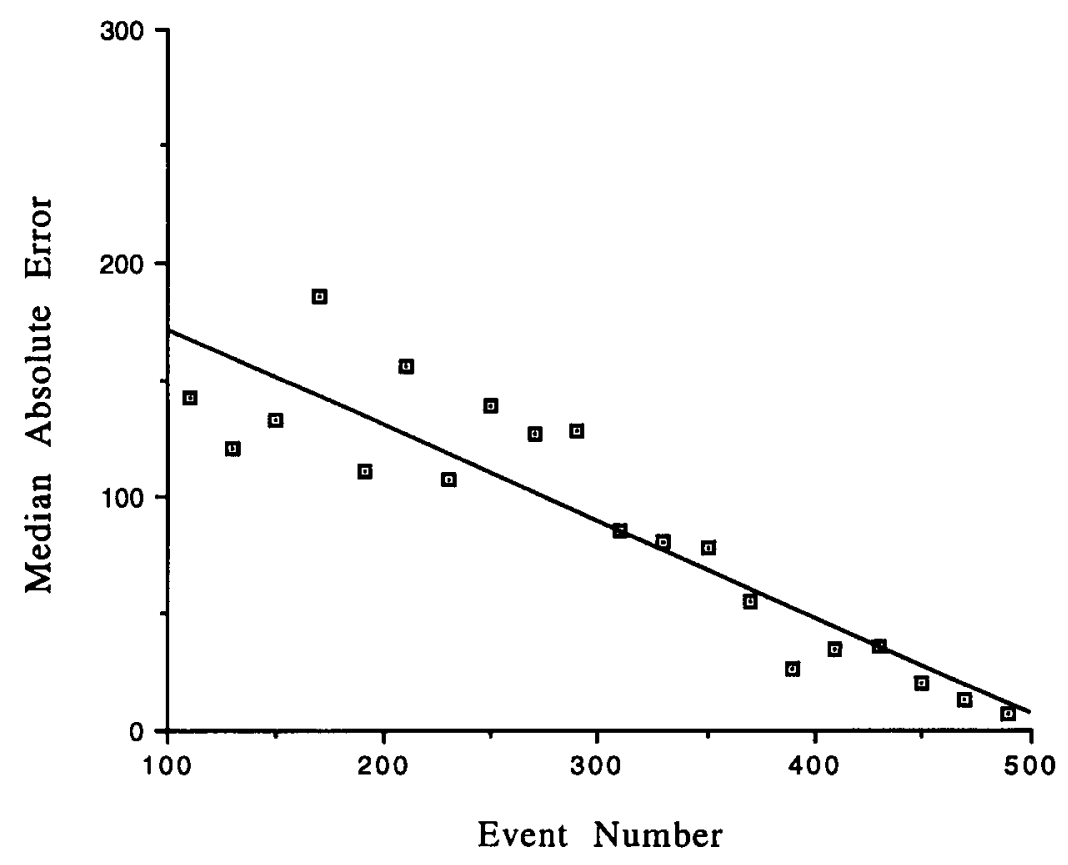

Figure 5. Median absolute error from Simulation 1 (single run) as a function of the event number.

theories of memory, but there were a few surveys in which people were asked to recall past prices. Generally in these studies, people were presented with a past date or time and then asked to recall either the level of prices in general or the price of a particular good at that time. So, for example, participants have been asked questions like the following: "Suppose you wish to buy something that costs $\$ 1,000$ today. How much do you think it would have cost one year ago, in ... ?" Or, "How much do you think 500 grams of butter cost 15 years ago, in ... ? (both questions from Kemp, 1987a).

Most of this research (e.g., Bates \& Gabor, 1986; Jonung \& Laidler, 1988; Kemp, 1984, 1987a; Vartia \& Mankinen, 1984) was carried out in countries and times

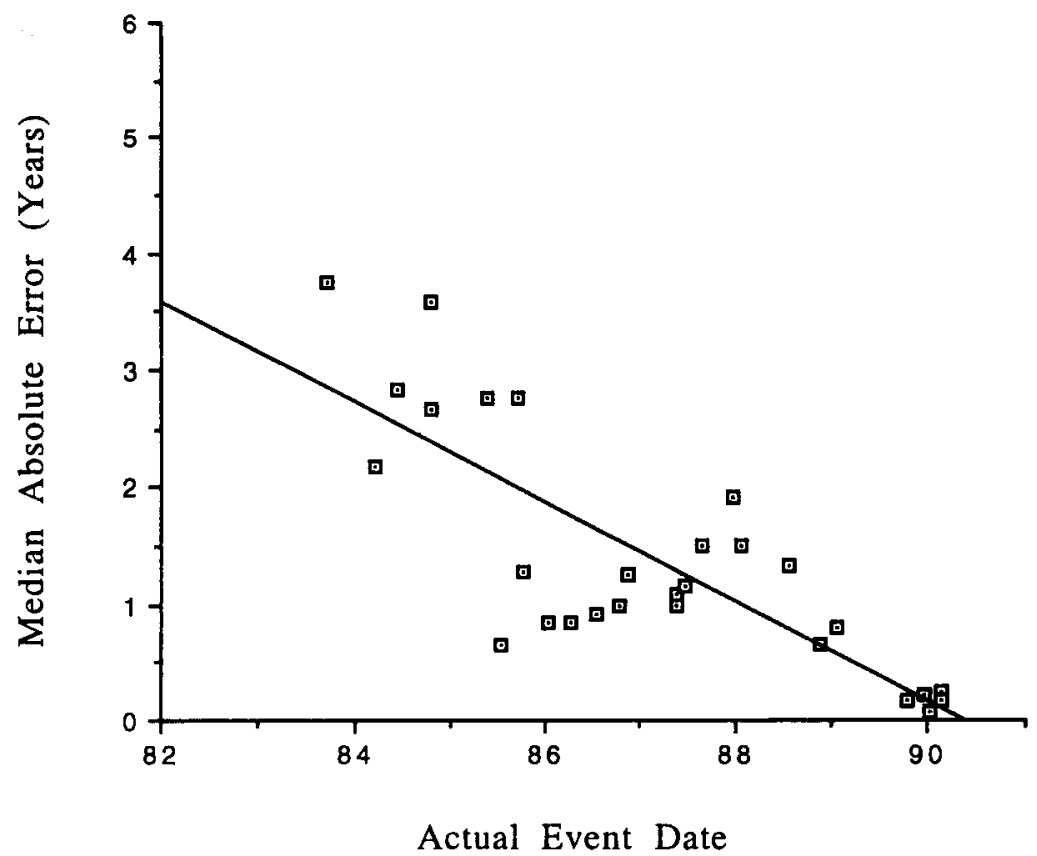

Figure 6. Median absolute error from the control condition of Kemp (1994, Experiment 1) as a function of the actual event date. 


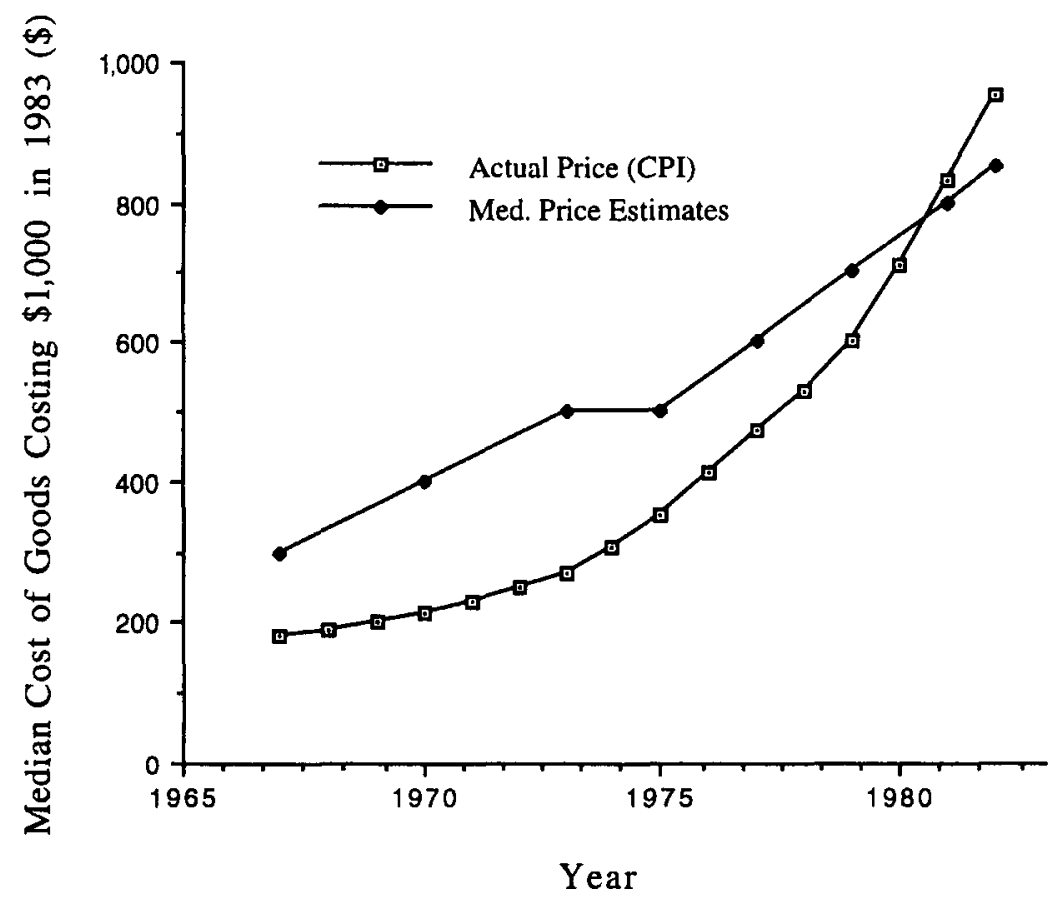

Figure 7. Median remembered price and actual price (taken from the New Zealand Consumer Price Index) of something costing $\$ 1,000$ in 1983 as a function of year. Data are from Kemp (1984).

where inflation had been moderately high $(8 \%-14 \%$ per annum) over the previous few years, and with people's memory for consumer prices, but similar effects have also been found in countries with histories of rather low inflation (Kemp, 1991) and where a commodity price (for wool) has been recalled by the producer (Kemp \& Willetts, 1996). The main effects were, first, that people are not very accurate at recalling past prices, and the level of accuracy generally decreased with the older prices; second, results are subject to a systematic bias that is reminiscent of that found with dates: Prices from more remote periods (normally longer than about 2 years) tend to be overestimated, whereas those from more recent periods are frequently underestimated. This occurs despite respondents' actually giving unbiased estimates of the rate of inflation itself (Kemp, 1984).

Figure 7 reproduces results obtained by Kemp (1984) in response to a series of questions about prices in general (see the first question above). A similar but less pronounced pattern of bias in response to similar questions was also reported by Bates and Gabor (1986). Vartia and Mankinen (1984) found underestimation of recent past prices of a basket of goods, but not overestimation of more distant prices. However, they asked prices only as far back as 5 years previous to the survey.

Kemp (1987a) asked the prices of specific goods in New Zealand (stamps, butter, and telephone costs) 1 year and 15 years previously. Generally, the prices from a year previous tended to be underestimated or accurate, whereas those from 15 years previous were overestimated. A study in a low-inflation economy (Kemp, 1991) showed accurate recall for the specific prices of a year previousthere was little change, in any case-but overestimation of the prices from 15 years previous.

People's memories for specific past prices of items seem to be at least partly reconstructed. New Zealand stamp prices were in fact subject in the 1970 s to rare but large price increases, and $40 \%$ of the respondents in Kemp (1987a) recalled 15-year-old stamp prices that had never existed at all. Again, even in inflationary times, prices of different commodities actually rise at quite different rates. However, respondents tend to recall the price changes of different items as more similar than they actually were, suggesting that people's memory for the prices of specific items might amalgamate memories of the past prices of other items besides those of the particular one requested (Kemp, 1991; Kemp \& Willetts, 1996).

At first sight, it might appear that the bias in memory for past prices depicted in Figure 7 could be easily explained by the bias in remembering past dates. Perhaps people remember the prices accurately, but because of the dating bias examined in previous sections, they misremember the time of the price. A little thought, however, should convince the reader that this explanation cannot be correct. It simply produces entirely the wrong prediction.

For example, if you are asked to remember the price of an item, the item-price memory that you take to be 5 years old will generally be older than 5 years--say, 
7 years. This is because dating bias generally makes more remote events seem more recent. However, the price of a 7-year-old item in inflationary times will actually be less than that of the 5-year-old item. Thus, dating bias alone would predict that relatively remote prices should be underestimated, not overestimated, as is actually found.

Clearly, simple application of dating bias will not explain the phenomenon. However, the resemblance between the price-memory and dating biases suggests that an extrapolation of the associative theory might explain it. Indeed, a theory that holds that there is nothing particularly special about time information ought to be able to explain it.

The following simulation applied and extended the associative model to price memory. Two additional assumptions were necessary. The first additional assumption is that price information is treated similarly to time information. That is, it is occasionally remembered in association with contexts, just as time information is.

The second assumption is that price information from any given period is rather more readily forgotten or is less likely to be available than time information. Some empirical justification can be found in the fact that present prices for items are often not known (particularly in times of inflation; see, e.g., Shamir, 1985). It would be difficult, on the other hand, to find many people who did not know the present month and year.

The theory presumes that when people are given a date and asked to name a generic price ("Suppose something costs $\$ 1,000$ today. How much do you think the same thing would have cost 10 years ago - that is, in ...?"), they first seek the nearest date they can associate with a context. Having found this, they then seek the closest context index to that which they have just found that has available price information. The second of these processes is identical to that used to seek time information in dating, and the first is effectively the reverse of it.

The following section outlines a simulation of people's ability to remember prices in general that extends the particular model used for the first simulation.

\section{SIMULATION 2}

\section{Method}

Parameters of the time-remembering process and the context process were the same as in Simulation 1, as was the number of time periods (500) and the number of repetitions.

Actual prices were calculated from the equation: price $=1,000$ $\times \exp [($ event -500$) / 220]$. The assumption of an exponential process is identical to the assumption of a constant rate of inflation. The price at Event Number 100 was 162.3 and that at Event 500 was 1,000 . This range of prices is comparable to the ranges investigated in the empirical studies cited earlier.

The price-remembering process was similar to the timeremembering process. The information to be remembered in this case was the price, and the price in any period was remembered with probability equal to $.007+.13 * \exp [($ event -500$) / A]$. The time constant $A$ was taken as 100 , the same as for the time information. (There seems to be no a priori reason why price information should be subject to a different rate of forgetting.) The constants .007 and .13 are about a third of the size of those used in the time-remembering equation to reflect the assumption that price information is less memorable than time information.

As in Simulation 1, the first part of the program set up the contents of the memory, and the second described the retrieval process. Ten events were chosen at intervals of 40 events, beginning with

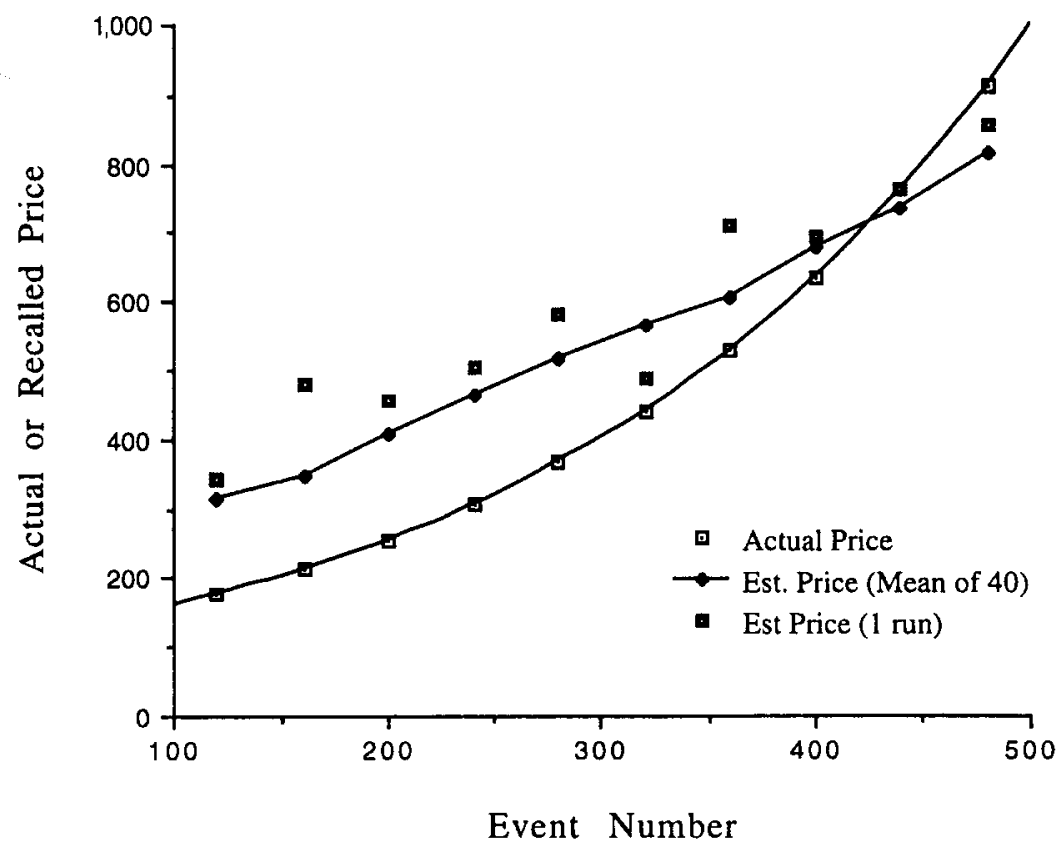

Figure 8. Actual or median remembered price as a function of the event number. Results from Simulation 2. The joined points show the mean obtained from 50 separate simulations, the disconnected points from a single simulation with 40 repetitions. 
120 and ending with 480 . For each given event number, the simulation first searched for that context with the event number nearest to the starting time. The initial context so found was then compared with the other contexts for which price information was remembered. The context that was closest (absolute difference) to the initial context was then selected, and its accompanying price information was taken as the estimated price.

\section{Results and Discussion}

Figure 8 shows the results of a single simulation and the mean result of 50 separate simulations (containing a total of 2,000 repetitions). Comparison with Figure 7, which portrays the comparable results from a study of price memory (Kemp, 1984), shows that the major features of actual data were reproduced by the simulation. Remote prices were overestimated by the simulation and very recent ones were underestimated, as they were in the actual results.

As for the previous simulation, it is easy to think of ways in which the principles of the associative theory might be ramified. It is likely that people's memories for prices in general are compounded of a number of rather different specific items, each of which could be modeled with its own particular price transformation. Memory for the price of a specific item, which appears to be an amalgam of the prices pertaining to the specific item and the more general price trend, would then reflect specific price information retained for that item and associated price information from other items.

\section{GENERAL DISCUSSION}

Overall, the results of the simulations presented here closely follow the results obtained from actual dating experiments. In particular, the theory predicts dating bias and the way in which the average dating error varies with elapsed time. Moreover, in the simulations and the data, forward telescoping prevailed: On average, events were dated too recently. Finally, a fairly straightforward extension of the theory predicted the pattern of estimation of inflated past prices.

The model presented here does not allow for reconstructive strategies or for other biasing factors such as boundaries, and the associative process has been made to do all the "work" in the simulations. This approach is necessary to establish that the proposed mechanism is actually capable of reproducing the pattern of the empirical results, particularly in situations where boundaries seem to have been of little importance. However, the research reviewed here indicates that a variety of different processes are used by different participants and in different circumstances, and a model that captures the full complexity of how people date past events or recall past prices might well have to include all these different processes. Some of these processes, at least, could be fairly easily incorporated into the kind of simulation model proposed here.

For example, respondents who are asked to give prices for the same item at a number of different times (Kemp, 1984) often respond by recalling prices that consistently increase with times closer to the present, presumably re- flecting their belief that prices rise in times of inflation but do not decrease. The present model does not feature that requirement (cf. Figures 7 and 8), but it would be straightforward to modify the model so that it would. Similarly, at least sometimes when people use landmarks to date events, they are able to estimate fairly accurately the time interval elapsing between the landmark and the target event (see, e.g., Loftus \& Marburger, 1983). In this situation, of course, it is hard to see how any dating bias would result. The model presented here does not predict people's frequent ability to remember the day of the week on which an event occurred, or whether it was a weekend or a week day (see, e.g., Larsen \& Thompson, 1995), but some component of the context index could be a weekly cyclic effect.

Neither the dating experiments nor the price estimation experiments whose results have been simulated here featured particularly limiting boundaries, but this is not true of all research situations. Boundary effects are fairly easily accommodated within the simulations outlined here. For example, an extra simulation was conducted where the far boundary in Simulation 1 was moved back to -300 (giving a total of 800 events and an additional "past" of 300 events), and all other parameters and procedures were kept constant. This simulation occasionally produced event estimates in the range of -300 to 0 , but so infrequently as to scarcely affect the median results. The simulation result in this case resembled the experimental finding (Kemp, 1994, Experiment 1) that participants in an unbounded dating condition often gave at least one date estimate outside the boundaries used in the bounded condition, but this did not produce a significant lowering of the median dates in that condition.

It is worthwhile to consider not only how the associative theory copes with existing data but also what new predictions it might generate and how these differ from those of other theories. One such prediction, that memory for dimensions other than time might also be subject to the same kinds of biases, has been considered here for the particular case of how people estimate past prices, but could be more widely applied. However, it should be noted that the associative theory is not the only theory claiming that memory is not chronologically organized and that the time of occurrence of events has no special status in it. Other reconstructive theories make a similar general prediction, although it has yet to be demonstrated that they account for any specific results.

One difference between the associative theory and the boundary effects theory is that, in the former, bias results from an "attractive" force (target events whose date is unknown are drawn to similar events with usable date information), whereas, in the latter, bias results from a "repulsive" force (away from the boundaries). A special prediction of the associative theory is that events will tend to be given date estimates that are like the dates of similar events.

There is some empirical support for this prediction. Lieury et al.'s (1979) observation that the extent of dating bias varied with the type of the event is consistent 
with it. Kemp (1987b) found that when participants were asked to date media or historical events on timelines that were marked with other media or historical events, there was a tendency for events to be placed near similar or related events.

Neither of these studies was specifically designed to test the associative theory. One that was (Kemp, 1996, Experiment 2) asked participants to date specific media events (e.g., "the assassination Rajiv Gandhi") and generic media events (e.g., "the assassination of a world leader"). Two predictions of the associative theory were investigated. First, the generic events should on average be dated more recently than the specific events. (This follows because of the tendency to forget more remote events.) Second, and more importantly, errors in dating specific events should be related to the dates given to the generic events. If a generic event is dated as very recent, then the specific event should tend to be dated too recently. Both predictions were upheld.

These results are probably better described as encouraging for the associative theory than as decisive support for it, especially as, to my knowledge, no studies have investigated whether people date their less well-known personal memories so as to shift them toward the times of occurrence of memories whose dates are better known. Yet such studies would probably provide better evidence for or against the associative hypothesis than would similar studies employing media or historical events because it should prove possible to make rather different predictions for different participants.

A rather more subtle prediction of the associative theory might also be better examined with reference to people's personal memories. In general, the theory predicts forward telescoping of remote memories, but it is possible to think of situations in which backward telescoping might prevail. Some existing research (e.g., Rubin, Wetzler, \& Nebes, 1986) suggests that particularly interesting periods do occur in people's lives. If a period containing rich associations and a number of well-remembered dates is succeeded by a "duller" period of one's life, events that occur in the latter that are nonetheless relatively similar to those occurring earlier should on average be dated as coming from the earlier period.

Friedman (1993) has claimed that remembering the specific times of events is unlikely to have been of much evolutionary consequence for us, and hence that it is unlikely that we use any consistent kind of time tagging. The present theory is consistent with this viewpoint, as are a number of other models of how we remember time information. An interesting and perhaps disturbing consequence of all these models is that there should be situations in which humans ought to be rather poor at inferring causation. This should be particularly true where there is no theoretical or obvious spatial link between two events and where there is some time delay between the events. In this case, the ability to infer cause would depend primarily on knowing that Event A has normally preceded Event B. But if this sequence cannot be remembered because the times are not known, then the inference cannot be made.

Finally, the theory presented here resembles those of Huttenlocher et al. (1990), Huttenlocher et al. (1988), and Rubin and Baddeley (1989) in trying to explain how dating and other biases can result without the need to assume a built-in bias in the way that humans represent the world. In the present model, the key psychological assumptions are the relatively uncontroversial ones that memory is an associative process and that older information is less likely to be accessible to recall than more recent information.

\section{REFERENCES}

ANDERSON, J. R. (1983). The architecture of cognition. Cambridge, MA: Harvard University Press.

ANDERSON, J. R. (1991). The adaptive nature of human categorization. Psychological Review, 98, 409-429.

ANDERSON, J. R., \& BOWER, G. H. (1974). Human associative memory. Washington, DC: Hemisphere

Baddeley, A. D., Lewis, V., \& Nimmo-Smith, I. (1978). "When did you last ... ?" In M. M. Gruneberg, P. E. Morris, \& R. N. Sykes (Eds.), Practical aspects of memory (pp. 77-83). London: Academic Press.

BARTLETr, F. C. (1932). Remembering: A study in experimental and social psychology. Cambridge: Cambridge University Press.

Bates, J. M., \& GABOR, A. (1986). Price perception in creeping inflation: Report on an inquiry. Journal of Economic Psychology, 7, 291314.

Bradburn, N. M., RiPs, L. J., \& SheVell, S. K. (1987). Answering autobiographical questions: The impact of memory and inference on surveys. Science, 236, 157-161.

Bratfisch, O., Ekman, G., Lundsberg, U., \& Kruger, K. (1971). Subjective temporal distance and emotional involvement. Scandinavian Journal of Psychology, 12, 147-160.

Brewer, W. F., \& Nakamura, G. V. (1984). The nature and function of schemas. In R. S. Wyer \& T. K. Sroll (Eds.), Handbook of social cognition (Vol. 1, pp. I 19-160). Hillsdale, NJ: Erlbaum.

Brown, N. R. (1990). Organization of public events in long-term memory. Journal of Experimental Psychology: General, 119, 297-314.

Brown, N. R., RIPS, L. J., \& Shevell, S. K. (1985). The subjective dates of natural events in very-long-term memory. Cognitive $P_{s y-}$ chology, 17, 139-177.

BURT, C. D. B. (1992). Retrieval characteristics of autobiographical memories: Event and date information. Applied Cognitive Psychology, 6, 389-404.

BURT, C. D. B., \& KEMP, S. (1991). Retrospective duration estimation of public events. Memory \& Cognition, 19, 252-262.

Conway, M. A. (1996). Autobiographical knowledge and autobiographical memories. In D. C. Rubin (Ed.), The construction of autobiographical memories (pp. 67-93). Cambridge: Cambridge University Press.

FERGUSON, R. P., \& MARTIN, P. (1983). Long-term temporal estimation in humans. Perception \& Psychophysics, 33, 585-592.

Friedman, W. J. (1987). A follow-up to "Scale Effects in Memory for the Time of Events": The earthquake study. Memory \& Cognition, $15,518-520$

Friedman, W. J. (1993). Memory for the time of past events. Psychological Bulletin, 113, 44-66.

FriedMAN, W. J. (1996). Distance and location processes in memory for the times of past events. In D. L. Medin (Ed.), The psychology of learning and motivation (Vol. 35, pp. 1-41). San Diego: Academic Press. 
Friedman, W. J., Gardner, A. G., \& Zubin, N. R. E. (1995). Children's comparisons of the recency of two events from the past year. Child Development, 66, 970-983.

FRIEDMan, W. J., \& HutTenlocher, J. (1997). Memory for the times of 60 Minutes stories and news events. Journal of Experimental Psychology: Learning, Memory, \& Cognition, 23, 560-569.

FRIEDMAN, W. J., \& KEMP, S. (1998). The effects of elapsed time and retrieval on young children's judgments of the temporal distances of past events. Cognitive Development, 13, 335-367.

FRIEDMAN, W. J., \& WILKINS, A. J. (1985). Scale effects in memory for time of events. Memory \& Cognition, 13, 168-175.

Huttenlocher, J., Hedges, L., \& Bradburn, N. (1990). Reports of elapsed time: Bounding and rounding processes in estimation. Jour nal of Experimental Psychology: Learning, Memory, \& Cognition, 16, 196-213.

Huttenlocher, J., Hedges, L., \& Prohaska, V. (1988). Hierarchical organization in ordered domains: Estimating the dates of events. Psychological Review, 95, 471-484.

INTRAUB, H., BENDER, R. S., \& MANGELS, J. A. (1992). Looking at pictures but remembering scenes. Journal of Experimental Psychology. Learning, Memory, \& Cognition, 18, 180-191.

JONUNG, L., \& LAIDLER, D. (1988). Are perceptions of inflation rational? Some evidence for Sweden. American Economic Review, 78, 1080-1087.

KEMP, S. (1984). Perception of changes in the cost of living. Journal of Economic Psychology, 5, 313-323.

KEMP, S. (1987a). Estimation of past prices. Journal of Economic Psychology, 8, 181-189.

KEMP, S. (1987b). Gestalt grouping effects in locating past events on timelines. Acta Psychologica, 64, 139-149.

Kemp, S. (1988). Dating recent and historical events. Applied Cognitive Psychology, 2, 181-188.

KEMP, S. (1991). Remembering and dating past prices. Journal of Economic Psychology, 12, 431-445.

KemP, S. (1994). Bias in dating news and historical events. Acta Psychologica, 86, 69-87.

KEMP, S. (1995). Effect of age on dating bias. Unpublished manuscript

KEMP, S. (1996). Association as a cause of dating bias. Memory, 4, 131 143.

KEMP, S., \& BURT, C. D. B. (1998). The force of events: Cross-modality matching the recency of news events. Memory, 6, 297-306.

KemP, S., \& WilLetTs, K. (1996). Remembering the price of wool. Journal of Economic Psychology, 17, 115-125.

LARSEN, S. F., \& ThOMPSON, C. P. (1995). Reconstructive memory in the dating of personal and public news events. Memory \& Cognition, 23, 780-790

Lieury, A., Aiello, B., Lepreux, D., \& Mellet, M. (1980). La rôle des repères dans la recuperation et la datation des souvenirs. L'Année Psychologique, 80, 149-167.

Lieury, A., Caplain, P., Jacquet, A., \& Jolivet, C. (1979). La contraction du temps dans la datation des souveniers anciens. L'Année Psychologique, 79, 7-22.

LinToN, M. (1975). Memory for real-world events. In D. A. Norman \&
D. E. Rumelhart (Eds.), Explorations in cognition (pp. 376-404). San Francisco: Freeman.

Loftus, E. F., \& Marburger, W. (1983). Since the eruption of Mt. St. Helens, has anyone beaten you up? Improving the accuracy of retrospective reports with landmark events. Memory \& Cognition, 11, 114120.

Means, B., \& Loftus, E. F. (1991). When personal history repeats itself: Decomposing memories for recurring events. Applied Cognitive Psychology, 5, 297-318.

Rubin, D. C., \& BadDELEY, A. D. (1989). Telescoping is not time compression: A model of the dating of autobiographical events. Memory \& Cognition, 17, 653-661.

Rubin, D. C., Wetzler, S. E., \& Nebes, R. D. (1986). Autobiographical memory across the lifespan. In D. C. Rubin (Ed.), Autobiographical memory (pp. 202-221). Cambridge: Cambridge University Press.

SHamiR, J. (1985). Consumers' subjective perception of price in times of inflation. Journal of Economic Psychology, 6, 383-398.

Smith, R. N., \& TomLinson, P. (1977). The development of children's construction of historical duration. Educational Research, 19, 163170.

SoRABJI, R. (1972). Aristotle on memory. London: Duckworth.

SQuire, L. R., \& Slater, P. C. (1975). Forgetting in very long-term memory as assessed by an improved questionnaire technique. Journal of Experimental Psychology: Human Learning \& Memory, 1, 5054.

STEvens, S. S. (1975). Psychophysics: Introduction to its perceptual, neural and social prospects. New York: Wiley.

Thompson, C. P. (1982). Memory for unique personal events: The roommate study. Memory \& Cognition, 10, 324-332.

Thompson, C. P., Skowronski, J. J., \& BETZ, A. L. (1993). The use of partial temporal information in dating personal events. Memory \& Cognition, 21, 352-360.

Thompson, C. P., Skowronski, J. J., Larsen, S. F., \& Betz, A. L. (1996). Autobiographical memory: Remembering what and remembering when. Mahwah, NJ: Lawrence Erlbaum.

Thompson, C. P., Skowronski, J. J., \& LEe, D. J. (1988). Telescoping in dating naturally occurring events. Memory \& Cognition, 16, 461. 468.

Vartia, P., \& Mankinen, R. (1984). Perceived and expected price changes in Finland. Weltwirtschaftliches Archiv, 120, 121-132.

WAGENAAR, W. A. (1986). My memory: A study of autobiographical memory over 6 years. Cognitive Psychology, 18, 225-252.

Warrington, E. K., \& Sanders, H. I. (1971). The fate of old memories. Quarterly Journal of Experimental Psychology, 23, 432-442.

WHITE, R. T. (1982). Memory for personal events. Human Learning, 1 , 177-183.

Wright, D. B., Gaskell, G. D., \& O'Muircheartaigh, C. A. (1997). Temporal estimation of major news events: Re-examining the accessibility principle. Applied Cognitive Psychology, 11, 35-46.

(Manuscript received June 16, 1997; revision accepted for publication March 13, 1998.) 